that no one would find the chapter rewarding today. Similarly, the exposition of the physics of ocean currents (Chapters XIII and XIV) amounts to little more than geostrophy and the Ekman spiral. Productive circulation theory did not take off until Sverdrup and R.O. Reid developed the idea of basin-scale motion forced by the wind-stress curl, Stommel discovered how the beta-effect makes the gyres asymmetric, and Carrier introduced boundary-layer analysis to simplify the mathematics. But all that happened in the late 1940's, after The Oceans was published.

Before computers, geostrophic velocities and volume transports had to be calculated by hand from the serial observations of temperature, sa- linity, and depth. Therefore an important part of the "dynamics" in The Oceans dealt with the procedure for these "dynamic computations". Perhaps only oceanographers over 50 years old are laden with memories of the interminable, soulsearing tedium of this work: the multiple steps with tables and graphs to reach values of specificvolume anomaly, the double vertical integrations of each of those series by graph, interval-averaging, and summation, and finally (still manually, still enlivened only by the rhythmic clunking of one's desk calculator) the horizontal differencing, level by level, to obtain the velocity and transport distributions. It is a blessing that this part of The Oceans is utterly obsolete.

\title{
The OCEans-Its Relevance Today in Biological OCEanography
}

\author{
By Sharon L. Smith
}

$\mathrm{M}$ ANY EXAMPLES of the important observations made over the past century are included in The Oceans. The description of nanoplankton on the filtration apparatus of Oikopleura has long been one of the most insightful observations in biological oceanography. Its combination of morphology, function, taxonomy and processes, all generated by simple, careful observation and deduction, is still a model of biological synthesis. The degree to which our understanding has not advanced in the intervening years is a surprising realization. The Oceans is full of descriptions of various faunal groups, speculations about their evolutionary history and ecological roles in the sea, and basic definitions that structure our thinking and discussion. The full history of the terms we use is not explained, and some terms are no longer commonly used, but it is clear that The Oceans has played a key role in providing widespread uniformity in some basic terminology of biological oceanography over the past fifty years. Many of the tables in the book provide information of continuing relevance; the conversion of silk number to aperture size for plankton netting is the most used page in my copy of the book.

S.L. Smith, Oceanographic and Atmospheric Sciences Division, Brookhaven National Laboratory, Upton, NY 11973 , USA.
Although much of the biological discussion in The Oceans is highly speculative, its statements of concepts, many yet to be tested, are still often quoted. For example, the general problem of how organisms in the sea avoid being lost to depth is discussed at great length, including the statement “. . . the means of adaptation are mostly along the lines of increased length of appendages, of spines or bristles, or of dorsoventral flattening of the body. . . ."Unfortunately, few quantitative investigations of this hypothesis exist, a situation which has only added confusion to recent attempts to study vertical fluxes of material in the sea. The speculative nature of the text, however, is also a strength because it presents the reader with opportunities to consider ways in which form, function, and populations in the sea came to be shaped as we know them. The evolutionary slant must reflect the focus of biological thought at the time the text was written. but it serves today as a refreshingly different point of view.

When one considers which portions of the biological text seem most "au courant" and which seem most outdated, one gains a sense of where our understanding has advanced over the past fifty years. One realm in which knowledge has seemed to grow enormously in the last half century is the benthos. Many of the benthic examples used in The Oceans (1942) came from the Challenger Expedition (1873-75) and from the synthesis and subsequent publications by Murray regarding that

\section{The speculative}

nature of the text... is also a strength . . . 
$\ldots$ the intertidal and

the open ocean are

both parts of a unified

whole... expedition. The deep sea is presented as a habitat that is quiescent, cold and dark, where food limitation is perhaps the primary constraint on life. Our present day concepts about the deep sea include a more dynamic, variable environment in which the seabed and its creatures are actively involved in geochemical processes and exchange between the seabed and the water column. Observations and experiments have revealed an active deep-sea fauna that ranges over large distances. The well known discoveries of hydrothermal vents, and their specialized fauna and food web based on chemosynthesis, have altered old concepts dramatically over the past decade or two.

Additionally, The Oceans contains numerous examples and discussion of the fauna of the intertidal zone and the specialized demands of that habitat. Perhaps because of its accessibility, research in the intertidal zone has been active for a reasonably long time, and many observations of earlier decades remain relevant today. Inclusion of the whole range of marine habitats in The Oceans, and the point of view that the intertidal and the open ocean are both parts of a unified whole, is one of the strengths of the text. Present day thinking about marine habitats has become highly specialized and fragmented. The attempt to present a synthesis including many habitats not only informs the reader of the variety of biological problems available for study (and most of these continue to confront us) but also demands that we step back and consider a broader context for our oceanographic investigations.

Among the most stimulating and presently valid sections of the book are the discussions of production, food-web structure, and the effects of the ocean's physical forces on populations and communities. For example, consider the description of the attributes of halibut eggs and larvae, the life cycle of the adult fish, and the currents of their Alaskan habitat found in The Oceans. It is substantially what has become known today as fisheries oceanography. And in a discussion of temperate production cycles that predates much of Gordon Riley's work, The Oceans emphasizes the importance of annual cycles in production and consumption of organic material and the need to compare rates of these properties in analyzing ecosystems. It seems as if in the intervening 50 years, we have succeeded only in gathering snapshots of oceanic ecosystems, many of which support The Oceans' description of pelagic processes. We have not made as many remarkable advances in our understanding as we would like to think we have. The Oceans emphasizes the interactions and influences of many aspects of the oceanic environment on its biological populations and processes. This defines interdisciplinary research, the focus of many ongoing and planned research programs.

\section{The OCEANS: The Geological Bookends}

By Dean A. McManus

$T$ L HE OCEANS Opens with a discussion of bottom topography and closes with a discussion of sediments. These chapters are not so much introduction and summary, however, as sturdy bookends to hold the Physics, Chemistry, and General Bi$o \log y$, of the book's subtitle. In fact, the last chapter seems to have been an afterthought, inasmuch as it was penned into the original typed list of chapters (SIO Archives Collection 81-123, v. 1, p. 8).

These two geological chapters appear to have been chiefly written by chemical oceanographer

D.A. McManus, School of Oceanography, University of Washington, Seattle, WA 98195, USA.
Richard Fleming. They are of value mainly for the sense of completeness they provide the book. As a contribution to geology, they suffer from the poor timing of their publication. Only a scant three years earlier, geologists had been blessed with that hefty classic Recent Marine Sediments, edited by Parker Trask, which is almost three-quarters the length of the bulky Oceans. Trask's book was widely used in geology departments and was even reprinted 16 years later. Nevertheless, I'm told that the two chapters from The Oceans were used by Fran Shepard in teaching his submarine geology course at Scripps during the 1940s.

Then in 1948 Shepard's own book, Submarine Geology, was published, to be followed two years 